\title{
REGULAÇÃO DE PRODUTOS PARA SAÚDE: EM BUSCA DAS MELHORES PRÁTICAS
}

Regulation of health products: striving for best practices

${ }^{1}$ Pontifícia Universidade Católica do Rio de Janeiro. Rio de Janeiro/RJ, Brasil. Correspondência: Daniela Trejos Vargas. E-mail: dvargas@puc-rio.br.

Recebido em: 11/10/2017. 


\section{Introdução}

A seção “Tema em Debate” deste número da Revista de Direito Sanitário centra-se novamente no marco regulatório existente no Brasil na área de produtos para a saúde. Os três artigos selecionados trazem uma abordagem com viés comparatista em diferentes áreas nas quais a Agência Nacional de Vigilância Sanitária (Anvisa) atua: regulação de materiais médicos, análise e registro de patentes farmacêuticas e controle ex post facto da periculosidade de medicamentos por meio do recall.

O direito à saúde, previsto na Constituição Federal de $1988^{1}$, concretiza-se por meio de um conjunto de políticas públicas de vigilância sanitária, regulação e controle sobre medicamentos e materiais médicos. $\mathrm{O}$ acesso a produtos de saúde seguros depende da existência de um sistema confiável de vigilância sanitária, além do trabalho de pesquisa e desenvolvimento por parte das empresas farmacêuticas. No caso de exames clínicos, a fidedignidade dos resultados depende diretamente da qualidade dos materiais médicos utilizados.

O destinatário final dos materiais e medicamentos é o cidadão, cujo direito à saúde o Estado tem o dever de resguardar e garantir. Ao comparar diferentes sistemas jurídicos, é possível identificar pontos no sistema nacional de vigilância sanitária e de registro de patentes farmacêuticas que podem ser aperfeiçoados, aprendendo com a experiência de outros países.

\section{Regulamentação dos materiais médicos no Brasil}

Os autores Michele Feitoza-Silva, Patrícia Fernandes da Silva Nobre, André Luis Gemal e Katia Christina Leandro propuseram-se a fazer uma resenha cronológica do arcabouço regulatório existente no Brasil sobre materiais médicos sob regime de vigilância sanitária.

A criação da Anvisa, no âmbito federal, permitiu uma evolução das normas sanitárias não apenas dos medicamentos mas também dos chamados "produtos médicos", que podem ter aplicação médica, odontológica ou laboratorial e que se destinam a "prevenção, diagnóstico, tratamento, reabilitação ou anticoncepção" (p. 125).

Os autores selecionaram e classificaram as normas referentes a materiais ou produtos médicos, incluindo os kits para diagnóstico in vitro e equipamentos, no período cronológico de 1999 a 2015. A partir da sistematização dessas normas, é possível correlacionar e demonstrar a frequência de assuntos publicados, a tendência de temas e, com isso, a importância que a vigilância sanitária deu a cada um desses temas.

\footnotetext{
${ }^{1}$ Artigos 6 196 e 200, incisos I e II. BRASIL. Constituição da República Federativa do Brasil de 1988. Disponível em: <http://www.planalto.gov.br/ccivil_03/constituicao/constituicaocompilado.htm>. Acesso em: 13 out. 2017.
} 
Especial cuidado deve ser tomado com os materiais importados, pois a entrada no mercado de produtos de procedência e qualidade duvidosas pode colocar em risco os usuários e os profissionais que os utilizam. Em resposta a isso, o novo regulamento técnico (de 2013) traz requisitos a serem cumpridos tanto por fabricantes nacionais como por estrangeiros.

O surgimento, em 2006, da ferramenta online Notivisa, sob a coordenação da Anvisa, facilitou e sistematizou as notificações, contribuindo para o aperfeiçoamento do conjunto regulatório nacional. Os autores defendem que a certificação compulsória é um propulsor de melhoria dos produtos efetivamente comercializados.

\section{Recall de Medicamentos}

Os autores Adirley Machado Alves e Elias Kallas Filho apresentam uma pesquisa de direito comparado sobre a regulação e o funcionamento do recall de medicamentos no Brasil e em Portugal.

No Brasil, a retirada do produto de circulação cabe ao distribuidor e também à Anvisa, mas os medicamentos já distribuídos não são incluídos. O ônus acaba recaindo sobre o usuário do medicamento, a quem é assegurada a troca sem custo. Em Portugal, o recolhimento dos medicamentos é feito também junto ao consumidor final, mostrando uma efetiva preocupação com a saúde do cidadão.

O grande problema apontado pelos autores no sistema brasileiro diz respeito à ausência de um canal centralizado de divulgação da informação sobre recall de medicamentos, como existe em Portugal. No Brasil, não temos mecanismo similar de centralização, o que prejudica que o Estado cumpra suas obrigações de preservar a saúde e os direitos do cidadão como consumidor. Ainda que o fabricante, o distribuidor e a própria Anvisa tenham cumprido rigorosamente todas as etapas do recall, não estarão cumprindo integralmente o dever de informar previsto na legislação consumerista brasileira. $\mathrm{O}$ consumidor que adquiriu o medicamento e que não teve acesso à informação sobre o recall, por deficiência no sistema de divulgação, pode continuar a utilizar um medicamento impróprio ou que cause dano à sua saúde.

\section{0 público e o privado, as patentes e a saúde: estudo da fraude de farmacêuticas na Itália comparado à legislação brasileira}

O terceiro artigo, das autoras Cristianne Maria Famer Rocha, Letícia Lassen Petersen e Lígia Daiane Fink dos Santos, mostra que, mesmo em uma área intensamente regulada, como é o sistema de registro de patentes farmacêuticas, podem subsistir práticas comerciais lesivas ao consumidor final dos medicamentos e também ao sistema público de saúde. As autoras trazem a lume uma situação ocorrida na Itália, onde duas grandes empresas farmacêuticas registraram, em momentos diferentes, patentes distintas do mesma substância química, resultando em medicamentos com nomes e 
finalidades distintas ${ }^{2}$ - o mais antigo, para tratamento oncológico e o mais recente, para degeneração macular. O "novo" medicamento, com prescrição diferente do primeiro, passou a ser comercializado a um preço exponencialmente maior que o mais antigo. As empresas acabaram condenadas na Itália por práticas anticoncorrenciais.

Essa estratégia comercial dos laboratórios é claramente lesiva aos consumidores e aos sistemas nacionais de saúde. Nesse caso em especial, as autoras qualificam a segunda patente como produto de fraude, pois, como o medicamento já era conhecido, não foram necessários investimentos suplementares em pesquisa e desenvolvimento que justificassem o valor cobrado pelo "novo" medicamento.

As autoras alertam para o fato de que essa estratégia comercial poderia estar sendo reproduzida no Brasil com esses mesmos medicamentos, visto que essas patentes estão registradas no Instituto Nacional de Propriedade Industrial (INPI), em respeito aos acordos internacionais em vigor (Acordo TRIPS da OMC) ${ }^{3}$. Ainda que o "novo" medicamento não tenha entrado na Relação Nacional de Medicamentos Essenciais (Rename), pode vir a impactar o sistema público de saúde por força da judicialização crescente de pedidos de fornecimento de medicamentos.

\section{Considerações Finais}

No Brasil, as patentes de medicamentos dependem da anuência prévia da Anvisa para serem concedidas. No artigo $8^{\circ}$ do Acordo TRIPS, encontramos como princípios norteadores do sistema internacional de proteção de patentes a possibilidade de adotar "medidas necessárias para proteger a saúde e nutrição públicas e para promover o interesse público" e também "medidas apropriadas para evitar o abuso dos direitos de propriedade intelectual por seus titulares". Assim, o Acordo TRIPS deixa clara a prevalência do interesse público sobre o privado, do coletivo sobre o individual, e, no caso de questões de saúde pública, explica a presença de duas autarquias federais - o INPI e a Anvisa - na análise de patentes de produtos farmacêuticos.

As diretrizes do INPI, indo além do previsto no Acordo TRIPS, incluem a possibilidade de proteger novos usos de produtos já conhecidos por meio de uma nova patente. Essa prática é conhecida como evergreening ${ }^{4}$ ou segundo uso da patente. No mecanismo de evergreening, em que uma nova patente é solicitada sobre o mesmo princípio ativo, só que destinado a outro uso, a empresa farmacêutica obtém a extensão da proteção patentária. $\mathrm{O}$ mau uso desse benefício como estratégia comercial pode dar azo a práticas anticoncorrenciais e retardar a entrada em

\footnotetext{
${ }^{2}$ Avastin ${ }^{\circledR}$, da Roche, e Lucentis ${ }^{\circledR}$, da Novartis.

${ }^{3}$ Sobre a aplicação do Acordo TRIPS no Brasil na área de medicamentos, veja CHAVES, Gabriela Costa; VIEIRA, Marcela Fogaça; REIS, Renata. Acesso a medicamentos e propriedade intelectual no Brasil: reflexões e estratégias da sociedade civil. Sur, Rev. Int. Direitos Human., São Paulo , v. 5, n. 8, p. 170-198, jun. 2008.

${ }^{4} \mathrm{Em}$ alusão às árvores que não perdem as folhas no inverno, permanecendo sempre verdes.
} 
domínio público do medicamento, inviabilizando uma maior difusão deste como medicamento genérico, cujo custo para o consumidor e para o sistema público de saúde é menor.

Verifica-se aqui um claro conflito entre o interesse privado da indústria farmacêutica - consubstanciado em um direito de propriedade que está protegido por lei e que cabe ao INPI reconhecer por força dos acordos internacionais vigentes - e o dever do Estado de assegurar o direito à saúde por meio da adoção de políticas públicas de universalização do acesso a medicamentos.

No caso de produtos vinculados à saúde, não basta assegurar os direitos dos consumidores, pois isso não garante que o direito à saúde seja adequadamente respeitado. Assim, no sistema de recall de medicamentos, substituir o produto ou reembolsar o consumidor é insuficiente, pois o desconhecimento sobre o recall o deixa sem efeito, colocando em risco a saúde daquele usuário que ainda tem o medicamento em casa.

Nosso sistema de regulação tem sido aperfeiçoado continuamente, como se pode verificar na melhoria do controle sobre a qualidade dos produtos médicos. Ainda assim, podemos aprender com as melhores práticas existentes em outros países, como é o caso do sistema unificado de informações sobre recall de medicamentos existente em Portugal. Ao mesmo tempo, e sem desrespeitar os acordos internacionais de proteção às patentes, podem-se rever práticas que prejudicam a universalização do acesso a medicamentos no sistema de saúde e lesam o consumidor, como a permissão do evergreening. Em saúde, a aplicação e a interpretação do direito interno e das convenções internacionais precisam sempre ser feitas à luz do princípio da dignidade da pessoa humana, assegurando ao mesmo tempo o direito à saúde e a proteção integral do consumidor.

\section{Referências}

CHAVES, Gabriela Costa; VIEIRA, Marcela Fogaça; REIS, Renata. Acesso a medicamentos e propriedade intelectual no Brasil: reflexões e estratégias da sociedade civil. Sur, Rev. Int. Direitos Human., São Paulo, v. 5, n. 8, p. 170-198, jun. 2008.

Daniela Trejos Vargas - Doutora em Direito Civil pela Universidade do Estado do Rio de Janeiro (UERJ); mestre em Direito Constitucional pela Pontifícia Universidade Católica do Rio de Janeiro (PUC-Rio); graduada em Direito pela PUC-Rio. Coordenadora Central de Graduação da PUC-Rio; professora de Direito Internacional Privado nos cursos de graduação e pós-graduação da PUC-Rio; integrante do Núcleo de Direitos Humanos da PUC-Rio. Rio de Janeiro/RJ, Brasil.E-mail: dvargas@puc-rio.br. 